\title{
Announcement
}

\section{The Cheryl Bennett Best Paper Award}

The Cheryl Bennett Best Paper Award was established to honor the lifetime achievements of Cheryl Bennett to the area of ergonomics for children, youths, and students. The purpose of the award is to honor the authors of a published paper in WORK who have advanced the body of knowledge in the area of ergonomics for children, youths, and students. It was Cheryl Bennett's passion to spread the word of children's ergonomics and it is with this Award that Cheryl's aspirations will grow in awareness and strength.

The award consists of a cash amount of US \$100 and a certificate of achievement. All papers submitted in a calendar year will be automatically eligible for the Award. The Cheryl Bennett Best Paper Award Committee will consist of four members of WORK's Editorial Board and the Editor-in-Chief. Yearly, published papers in the preceding year will be reviewed in January and the Award recipient(s) will be announced in March. The criteria for selection will be based on the quality of contribution, as documented in the paper, to the advancement of knowledge in the area of ergonomics for children, youths, and students. 